\title{
Two New Species of Tremex Jurine (Hymenoptera: Siricidae) from Japan
}

\author{
Ichiji Togashi \\ 1-chome. Honmachi, Tsurugi-machi, Ishikawa Prefecture 920-21, Japan
}

(Received 4 November 1996; Accepted 7 February 1997)

\begin{abstract}
Two new species of woodwasps, Tremex okinawensis sp. nov. and T. kaedei sp. nov., from Japan are described and illustrated, and a key is provided for the Japanese spccies of Tremex.

Key Words: Tremex, Siricidae, Symphyta, Japan, food plant, Acer sp.
\end{abstract}

I recently received 7 specimens ( 2 females and 5 males) of siricid woodwasps from Professor S. Azuma, University of the Ryukyus, Okinawa Prefecture, and Mr. A. Abe, Hirosaki City, Aomori Prefecture, Japan. These specimens belong to the fuscicornis-group (pronotum short with midlength shorter than OCL) of the genus Tremex Jurine. As a result of comparative studies of the fuscicornis-group, I concluded that these specimens represent two new species, which are described and illustrated in this paper.

\section{Key to the Japanese species of Tremex}

1. Basal half of antenna black and apical half white …........ apicalis Matsumura

-. Antenna fulvous or brownish black ……......................................... 2

2. Pronotum long, its midlength nearly as long as OCL (ratio about 1.0:1.0) $\quad \cdots \quad 3$

-. Pronotum short, its midlength shorter than OCL (ratio about 1.0:1.3-1.6) $\quad \cdots 4$

3. Antenna brownish black; 8th tergite nearly as long as three preceding tergites combined; precornal basin nearly as long as broad

longicomis Konow

-. Antenna fulvous; 8 th tergite nearly as long as four preceding tergites combined; precornal basin broader than long …............................. contractus Maa

4. Anterior half of 8 th tergite reddish yellow and posterior half black (Fig. 7); basal $3 / 4$ of 2 nd tergite reddish yellow but $1 / 4$ black (Fig. 7); basal $1 / 3$ of hind basitarsus pale milky white, posterior $2 / 3$ pale reddish yellow (Fig. 4); precornal basin slightly broader than long (ratio about 1.3:1.0) (Fig. 8)

.................................................................. okinawensis sp. nov.

-. Eighth tergite with black band in middle (sometimes posterior half with two reddish yellow maculae or posterior half black) (Fig. 16); 2nd tergite reddish yellow (Fig. 16); hind basitarsus pale yellowish white (Fig. 13); precornal basin

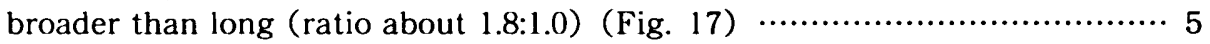

5. Eighth tergite shorter than three preceding tergites combined (ratio about 1.0:1.2) (Fig. 16); mesoscutum black (Fig. 12); 1st tergite entirely black (Fig.

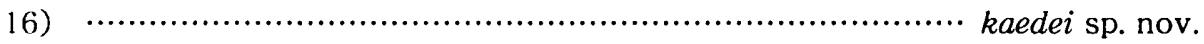


-. Eighth tergite nearly as long as three preceding tergites combined; mesoscutum black with reddish brown macula; lateral sides of 1 st tergite with reddish yellow

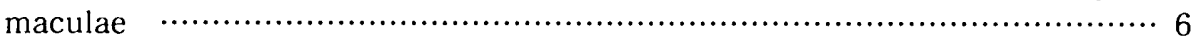

6. Mesoscutellum black; middle segments of antenna longer than broad; sheath shorter than basal plate (ratio about 1.0:1.3) ….......... fuscicornis (Fabricius)

-. Mesoscutellum reddish brown; middle segments of antenna slightly broader than long or nearly as long as broad; sheath much shorter than basal plate (ratio about 1.0:2.7)

nakanei Takeuchi

\section{Tremex okinawensis sp. nov.}

(Figs 1-9)

Female. Length $24 \mathrm{~mm}$, including cornus. Head reddish yellow with following parts black: malar space, anterior margin of clypeus, and mandible. Antenna reddish yellow. Thorax reddish yellow with following parts black: central portion and lateral sides of scutum (Fig. 3), metascutellum, metapostnotum, most of mesopleuron, and mesosternum. Wings yellowish hyaline; Cell $b m, 1 r$, and basal $1 / 3$ of $2 r$ of forewing infuscate; basal portion of anal cell of forewing infuscate; stigma and veins mostly fulvous. Legs reddish yellow but hind coxa, trochanters, and femora black; basal $1 / 3$ of all tibiae and hind basitarsus yellowish white (Fig. 4). Abdomen black with following parts yellow to reddish yellow (Fig. 7): front margin of 1st tergite, basal
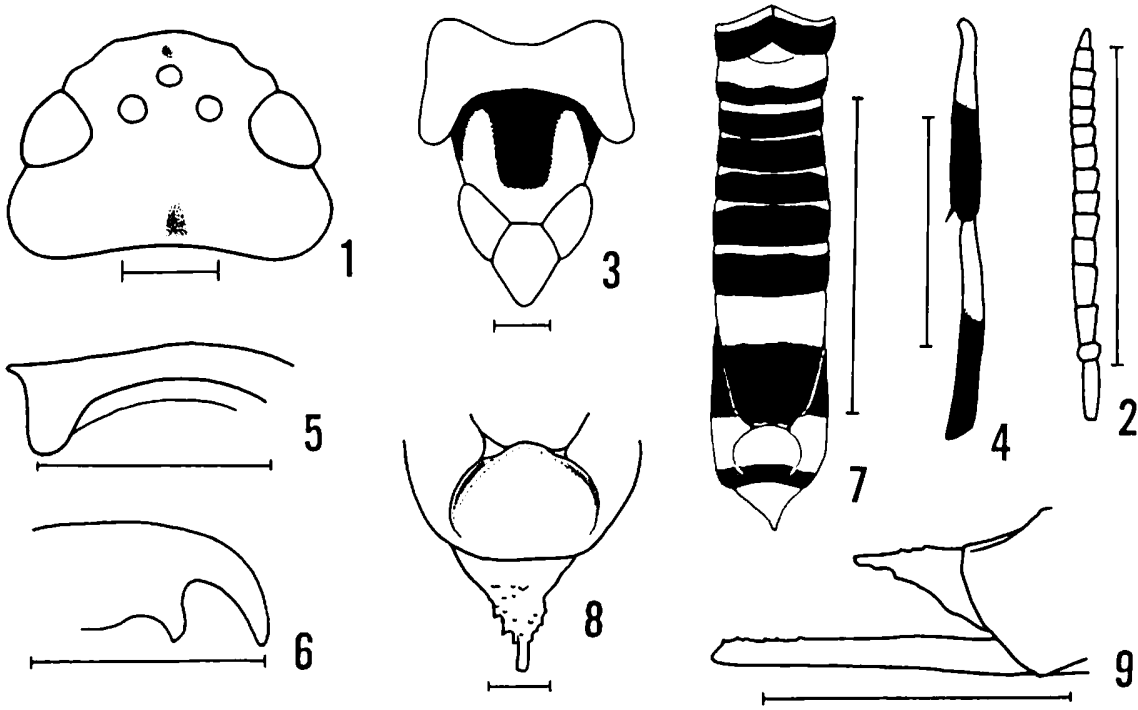

Figs 1-9. Tremex okinawensis sp. nov. - 1, head, dorsal view; 2, antenna, dorsal view; 3 , thorax except for metapostnotum, dorsal view; 5 , inner tibial spur of fore leg, lateral view; 6 , tarsal claw, lateral view; 7, abdomen, dorsal view; 8 , precornal basin and cornus, dorsal view; 9, cornus and sheath, lateral vicw. Scale for 1, 3 and 8: $1 \mathrm{~mm}$; scale for 2,4 and $9: 5 \mathrm{~mm}$; scale for 5 and 6 : $0.5 \mathrm{~mm}$; scale for $7: 10 \mathrm{~mm}$. 
$2 / 3$ of 2 nd tergite, basal $1 / 4$ of 3 rd tergite, basal margins of 4 th to 6 th tergites except for interruption in middle of each, basal $1 / 4$ of 7 th tergite, basal half of 8 th tergite, apical half of 9 th tergite except for posterior margin, cornus, all sternites except for lateral sides of 4 th to 8 th; and sheath reddish brown.

Head from above triangular (Fig. 1); vertex with longitudinal depression; OOL: POL : $\mathrm{OCL}=0.6: 1.0: 2.7$; area just in front of anterior ocellus with short, shallow depression.

Antenna 15-segmented (Fig. 2), more than half as long as costa of forewing (ratio about 1.0:1.5); 3rd antennal segment slightly shorter than 4th (ratio about 1.0:1.2); relative lengths of basal five segments about 3.0:1.0:1.7:2.1:1.5.

Thorax: pronotum short, its midlength shorter than OCL (ratio about 1.0:1.5). Legs: hind tibia nearly as long as hind basitarsus (Fig. 4); inner tibial spur of fore leg as in Fig. 5; tarsal claw as in Fig. 6.

Abdomen: 8th tergite nearly as long as three preceding tergites combined (ratio about 1.0:1.0); precornal basin broader than long (ratio between breadth and length about 1.3:1.0) (Fig. 8); cornus as in Figs. 8 and 9; sheath much more than half as long as basal plate (ratio about 1.0:1.2).

Punctation. Head and thorax except for mesopleuron and mesosternum distinctly, closely, and reticulately punctate; mesopleuron and mesosternum distinctly and evenly punctate, interspaces between punctae shiny. Abdominal tergites shagreened.

Male. Unknown.

Food plant. Unknown.

Distribution. Japan (Okinawa).

Holoty pe. Female, Benoki, Kunigami-son, Okinawa Island, 3. V. 1971, K. Miyagi leg., deposited in the collection of the National Science Museum (Nat. Hist.), Tokyo.

Etymology. Named for Okinawa, the type locality.

Remarks. This new species runs to T. guangchenii Xiao et $\mathrm{Wu}$ in Xiao and Wu's (1983) key, but $T$. okinawensis is distinguished from $T$. guangchenii by the coloration of the 8 th tergite, antenna, and sheath (in T. guangchenii, the front margin of the 8th tergite and the 3rd to 10 th antennal segments are black, and the sheath is brownish black), the form of the precornal basin (in T. guangchenii, the precornal basin is transverse, with a ratio between breadth and length of about 1.5:1.0), and differences in the ratio between OOL, POL, and OCL.

Tremex kaedei sp. nov.

(Figs 10-20)

Female. Length $30 \mathrm{~mm}$, including cornus. Head reddish yellow with following parts dark brown to black: vertex (Fig. 10) and apical half of mandible. Antenna reddish yellow. Thorax reddish yellow with following parts dark brown to black: longitudinal line at center of pronotum (Fig. 12), scutum, mesoscutellum, metascutellum, mesopleuron, and mesosternum. Wings yellowish hyaline; apical portion of Cell $b m, 1 r$, and $2 r$ of forewing infuscate. Legs: all coxae and all femora except for basal portions and knees black; all trochanters, as well as basal portions and knces of all femora, reddish brown; basal halves of all tibiae pale yellow and apical halves pale reddish yellow; fore and mid tarsi pale reddish yellow; hind tarsus 

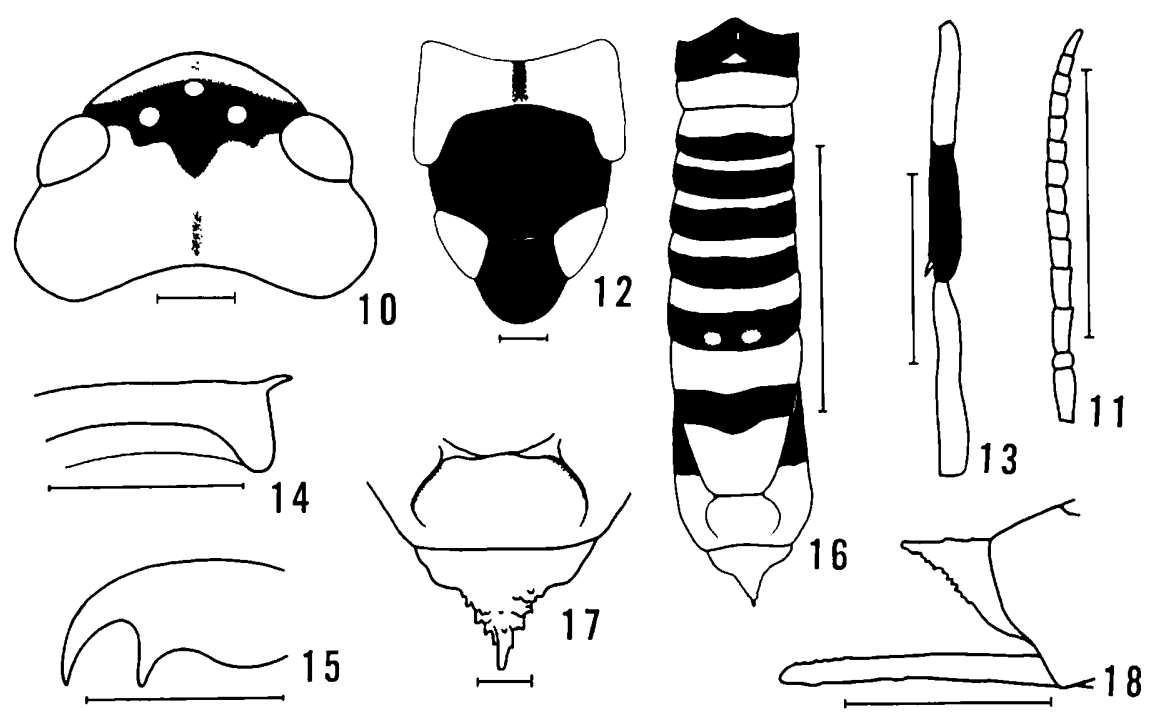

Figs 10-18. Tremex kaedei sp. nov._-10, head, dorsal view; 11, antenna, dorsal view; 12, thorax except for metapostnotum, dorsal view; 13, hind tibia and basitarsus, lateral view; 14, inner tibial spur of fore leg, lateral view; 15, tarsal claw, lateral view; 16, abdomen, dorsal vicw; 17 , precornal basin and cornus, dorsal view; 18, cornus and sheath, lateral view. Scale for 11, 13 and 18: $5 \mathrm{~mm}$; scale for 14 and 15: $0.5 \mathrm{~mm}$; scale for $16: 10 \mathrm{~mm}$.

whitish yellow. Abdomen black with following parts yellow to reddish yellow: posterior $2 / 3$ of 2 nd tergite, anterior half of 3rd tergite, anterior half of 6 th and 7 th tergites, anterior $1 / 3$ and posterior $1 / 3$ of 8 th tergite, posterior half of 9 th tergite, precornal basin, and cornus; sheath dark reddish brown.

Head from above triangular (Fig. 10); vertex with longitudinal depression; OOL:POL:OCL $=0.5: 1.0: 2.3$; area just in front of anterior ocellus with short, shallow depression.

Antenna 14-segmented (Fig. 11), more than half as long as costa of forewing (ratio about 1.0:1.5); 3rd antennal segment nearly as long as 4 th; relative lengths of basal five segments about 3.8:1.0:3.0:2.8:2.1.

Thorax: pronotum short, its midlength shorter than OCL (ratio about 1.0:2.0). Legs: hind tibia longer than hind basitarsus (ratio about 1.0:0.7) (Fig. 13); inner tibial spur of fore leg as in Fig. 14; tarsal claw as in Fig. 15.

Abdomen: 8th tergite shorter than three preceding tergites combined (ratio about 1.0:1.2); precornal basin much broader than long (ratio between breadth and length about 1.8:1.0); cornus as in Figs 17 and 18; sheath more than half as long as basal plate (ratio about 1.0:1.6).

Punctation. Head distinctly and rather closely punctate; thorax except for pronotum distinctly, closely, and reticulately punctate, but mesopleuron and mesosternum distinctly and rather evenly punctate, interspaces between punctae shiny. Pronotum granulated. Abdominal tergites shagreened.

Male. Length $19 \mathrm{~mm}$. Body black with following parts reddish yellow to reddish 
brown: cheek, supraclypeal area, tegula, apical portion of lateral lobes of mesoscutellum; 4 th to 8 th tergites except for interruption in middle of 4 th and 5 th tergites; posterior half of 4 th to 8 th sternites, and central portion of subgenital plate. Male genitalia rather dark reddish brown.

Antenna black but apical portion of scape and pedicel dark reddish brown.

Wings hyaline, apical $2 / 3$ of forewing infuscate.

Legs: all coxae, trochanters, and femora, as well as hind tibia and tarsus, dark reddish brown to black; fore and mid tibiae and tarsi reddish brown.

Subgenital plate and posterior margin of 8th sternite as in Fig. 19; male genitalia as in Fig. 20.

Food plant. Acer sp. (Japanese name: kaede).
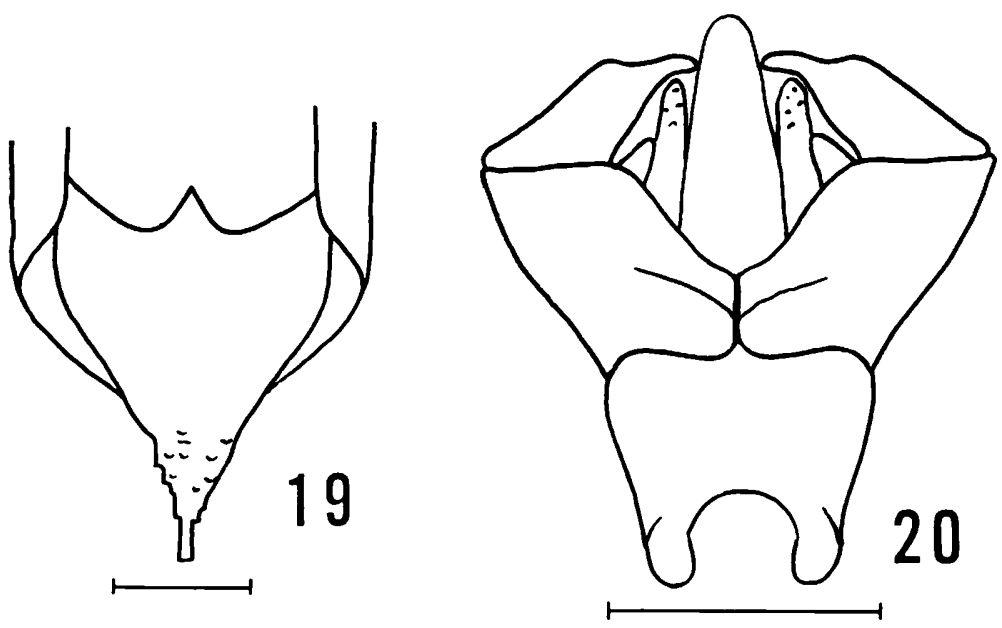

Figs 19 and 20. Tremex kaedei sp. nov. _- 19, 8th sternite and subgenital platc, ventral view; 20, genitalia, ventral view. Scale for 19 and 20: $1 \mathrm{~mm}$.

Distribution. Japan (Honshu).

Type series. Holotype: female, Hirosaki City, Aomori Pref., 11. IV. 1976, bred from Acer sp. (S. Satoh leg.), deposited in the collection of the National Science Museum (Nat. Hist.), Tokyo. Paratypes: 4 males, same data as for holotype; 1 male, Oirase, Fukaura-machi, Nishitsugaru-gun, Aomori Pref., 21. VI. 1973, Abe leg. One paratype deposited in the collection of the National Science Museum (Nat. Hist.), Tokyo, one paratype preserved in the National Museum of Natural History, Washington, D.C., and the other 3 paratypes in my collection.

Etymology: Genitive form derived treating the food plant's Japanese name as a masculine Latin noun.

Remarks. This new species runs to T. fuscicormis (Fabricius) in Takeuchi's (1955) key, but T. kaedei is distinguished from $T$. fuscicornis by the length of the 8 th tergite (in $T$. fuscicornis, the 8th tergite is nearly as long as the three preceding tergites combined, ratio about 1.0:1.0), by the length of the 3rd antennal segment (in T. fuscicornis, the 3rd antennal segment is shorter than the 4 th, ratio about 1.0:1.2), 
and by the length of the sheath (in T. fuscicornis, the sheath is much more than half as long as the basal plate, ratio about 1.0:1.3).

\section{Acknowledgments}

I express my thanks to Dr. David R. Smith, USDA, Washington, D.C., for reading through this manuscript and his kind advice. I am indebted to Professor S. Azuma, University of the Ryukyus, Okinawa Prefecture, and Mr. A. Abe, Hirosaki City, Aomori Prefecture, for their kindness in giving me the opportunity to examine the specimens. And also, I am indebted to Dr. A. Shinohara, National Science Museum (Nat. Hist.), Tokyo, for lending me specimens of $T$. fuscicornis.

\section{References}

Takeuchi, K. 1955. Siricidae of Japan (Hymenoptera). Akitu 4: 1-4. (In Japanese, with English summary).

Xiao G.-r. and Wu J. 1983. The siricid wood wasps of China (Hymenoptera, Symphyta). Scientia Silvae Sinicae (Mem. of For. Entom.): 1-29. (In Chinese, with English summary). 